\title{
Perceived Self-Efficacy and Adaptation to Climate Change in Coastal Cambodia
}

\author{
Mengieng Ung 1,*, Isaac Luginaah 1,+, Ratana Chuenpagdee 2,+, and Gwyn Campbell 3,+ \\ Received: 7 October 2015; Accepted: 14 December 2015; Published: 24 December 2015 \\ 1 Department of Geography, Western University, London, ON N6A 5C2, Canada; iluginaa@uwo.ca \\ 2 Department of Geography, Memorial University of Newfoundland, St. John's, NL A1B 3X9, Canada; \\ ratanac@mun.ca \\ 3 Indian Ocean World Centre (IOWC), Montréal, Quebec, QC H3A 1X9, Canada; Gwyn.Campbell@mcgill.ca \\ * Correspondence: mung2@uwo.ca; Tel.: +1-519-661-2111 (ext. 82818); Fax: +1-519-661-3750 \\ + These authors contributed equally to this work.
}

\begin{abstract}
In response to climate change at different spatial scales, adaptation has become one of the focal points of current research and policy developments. In the context of coastal Cambodia, there is little research on local level adaptation to climate change. Using ordinal logistic and logistic regression analyses, this study examines the relationship between perceived self-efficacy and anticipatory and reactive adaptation to climate change among 1823 households in coastal communities in Cambodia. Findings indicate that individuals who reported higher categories of self-efficacy were more likely to report both anticipatory $(\mathrm{OR}=1.74, p<0.001)$ and reactive adaptation ( $\mathrm{OR}=3.61, \mathrm{p}<0.001)$ measures. Similary, tndividuals who had higher education had higher odds of reporting anticipatory adaptation $(\mathrm{OR}=1.71, \mathrm{p}<0.001)$ and reactive adaptation $(\mathrm{OR}=1.63, \mathrm{p}<0.05)$ when compared with those without formal education. Participants who have been living in their current residence for six years or more were more likely to report anticipatory adaptation $(\mathrm{OR}=1.09, p<0.05)$ and reactive adapation $(\mathrm{OR}=1.22, \mathrm{p}<0.001)$ compared with those who had lived there for a shorter duration of time. Region of residence was positively associated with both anticipatory and reactive adaptation. In this context, it is important to note that individuals in the most agriculture-dependent and climate sensitive province reported the least anticipatory and reactive adaptation measures. Policy makers should target empowerment of the most vulnerable population to facilitate better adaptation behavior, and mainstreaming of knowledge on climate change adaptation through both formal and informal education at the community level.
\end{abstract}

Keywords: perceived self-efficacy; anticipatory and reactive adaptation; ordered logistic and logistic regression; policy; coastal Cambodia

\section{Introduction}

The impact of climate change on humans has become one of the most prominent issues on the international agenda especially over the past few decades. The impacts associated with climate change vary within and between places due to multiple factors including physical features, coping capacities, and sensitivities [1,2]. Climate change mitigation and adaptation are concepts that have evolved in climate change discourse. While the former endeavors to avoid the unmanageable, the latter is aimed at managing the unavoidable [3]. Although mitigation was predominant in international climate policy debates in the 1990s and early 2000s, lately growing attention (in both theory and practice) is being given to adaptation. In fact, adaptation to climate change has become one of the prominent focal points of current policy development and debates [4-7]. According to Smit and Pilifosova (2003), "adaptation is important in climate change response in two ways: the assessment of impacts and vulnerabilities, and the development and evaluation of response options" [8] (p. 188). 
Given the rate at which the climate is changing and the potential adverse impacts associated with this change, adaptation "is no longer tomorrow's choice, but today's imperative" [3] (p.187). In developing countries particularly, where high dependency on climate-sensitive natural resources and elevated impact of climate change persists, adaptation has been one of the focal points of current development discussion $[9,10]$.

In the climate change literature, adaptation specifically refers to "adjustment in natural or human systems in response to actual or expected climate stimuli or their effects, which moderates harm or exploits beneficial opportunities" [11] (p. 982). Adaptation has been framed in an inconsistent manner in the literature. In terms of ownership, adaptation may be considered as private or public, that is whether individuals or state institutions initiate the action. Depending on whether it is spontaneous or not, adaptation can be autonomous or planned. Autonomous adaptations are initiatives that occur naturally by private actors without intervention of public agencies. Autonomous adaptation includes changes in livelihood practices such as using seasonal climate forecasting to reduce production risk, altering the timing or location of cropping activities; and wider use of technologies to"harvest" water, conserve soil moisture (e.g., crop residue retention), and to use water more effectively in areas with rainfall decreases [9]. Planned adaptation involves deliberate policy decisions on the part of public agencies. According to Tol et al., (2008), it requires conscious intervention using information on observed and anticipated climate change and by reviewing the suitability of current and planned practices, policy, and strategies [12].

On the basis of timing, adaptation may be anticipatory or reactive [12,13]. Anticipatory adaptation occurs prior to the climate-induced event whereas reactive adaptation happens in the aftermath of the climate-induced event. Anticipatory adaptation involves foreseeing, planning, and preparing in order to reduce exposure of the future risks of the climate-induced event. Reactive adaptation, informed by direct experience, perpetuates or exacerbates exposure to impacts $[14,15]$. Characterizing or framing climate change adaptation as either anticipatory or reactive is not entirely unproblematic. In reality, the set of climate adaptation options available to individuals, from time to time, is more complex and consists of a continuum of several potential adaptive actions. This means that at a specific time, an individual may simultaneously act in manner that is anticipatory in one respect, and reactive in another, depending on the specific adaptation option that is chosen. For instance, a farmer may purchase flood insurance only for personal belongings (anticipatory) and defer crop insurance due to limited financial resources (reactive) until the climate-induced event occurs. In this study, the analysis was limited to the dichotomous framing of climate change adaptation (anticipatory vs. reactive) since we were interested in the simplest and parsimonious explanation of the process of adaptation. The knowledge gained will then serve as basis for future comprehensive analysis of the phenomenon of climate change adaptation.

Adaptation is also conceptualized both as a process and a condition, whereby it is not only seen in terms of changing behavior, but also changes in cognitions, which are socially constructed and negotiated [8,16-18]. For this reason, adaptation can either be an end in itself (outcome or state) or a means to an end (process or mediating mechanisms). Either way, Narayan-Parker (2005) suggests a psychological dimension to adaptation and indicates that perceived self-efficacy is one of the key elements of adaptive capacity [19]. Previous research suggests strong linkages from beliefs through distress and self-efficacy to psychological adaptation that can lead to behavioral engagement [20]. This brings into sharp focus the issue of self-efficacy (belief in personal capability), which is often neglected in the climate change adaptation literature. Although perceived self-efficacy has previously been used in climate change response studies, these scholarly works have predominantly focused on mitigation behaviors [21]. Studies that thoroughly examine perceptions and understanding of adaptation behavior using perceived self-efficacy remain largely unexplored. This study contributes to the literature by attempting to fill this gap, but also adds to the scant literature on climate change adaptation in Cambodia [22].

Cambodia is highly vulnerable to climate change due to the fact that a large proportion of the population is dependent on climate-sensitive livelihoods such as agriculture and fisheries [23]. The National Committee for Disaster Management of Cambodia estimated the cost of destruction at 
\$521 million with 220,000 ha of rice fields destroyed, 247 deaths, and 1.2 million people affected during the floods in 2011 [24]. In more recent years, Cambodia has witnessed more frequent and severe storms, floods, and droughts, resulting in considerable fatalities and significant economic losses [25]. Elevated sea level, high tide, beach erosion, seawater intrusion, and storm surges place coastal zones in danger by jeopardizing coastal fisheries, mangrove forests, beach resorts, and seaports. In response to sudden and severe changes in climate, the Royal Government of Cambodia (RGC) took a critical first step by adopting the National Adaptation Program of Action to Climate Change (NAPA) for Cambodia in 2006 [25]. The Cambodia NAPA was formulated through a participatory process, which also involved rural communities, stakeholders, and policy makers. The Cambodia NAPA objectives include understanding the characteristics of climate hazards, understanding coping mechanisms at the local level, identifying existing programs addressing climate hazards, and characterizing and prioritizing adaptation to climate change [25].

\section{Theoretical Framework: Perceived Self-Efficacy}

The notion of self-efficacy is a central concept in health communication research $[13,26]$. It has been widely developed in the Health Belief Model [27], Protection Motivation Theory [28,29], the Theory of Planned Behavior (TPB) [30], and Social Cognitive Theory [31].

According to Bandura's Social Cognitive Theory [31,32], perceived self-efficacy is the extent to which people believe that they are capable of doing specific tasks in order to achieve certain goals. It exerts its influence through four major processes: selection, motivational, affective, and cognitive dimensions. Grothmann and Patt (2005) suggest two cognitive appraisal processes that people would undertake in deciding to protect themselves and hence adapt to climate change impacts. These are "risk appraisal-the perceived probability of being exposed to risk and its perceived severity; and adaptation appraisal - the ability to avert being harmed by the threat, along with the costs of taking such action and results in an awareness of perceived adaptive capacity". [17] (p. 5). Irrespective of whether an individual perceives some threats to be low or high, that individual will engage in appraising their efficacy $[33,34]$. However, it has been suggested that those who perceive or believe the threats or hazards to be high, are more likely to take protective action to avert the harm. An individual's belief in his or her capacity to execute behaviors necessary to reduce or avert harm is known as self-efficacy [32,35]. Perceived self-efficacy reflects confidence in the ability to exert control over one's own behavior and social environment. Hence, the concept of self-efficacy is considered crucial in understanding human behavior [36]. Lately, self-efficacy, as a concept, is increasingly being used to understand human responses to climate change [37] although its use has been mainly restricted to studies on mitigation rather than adaptation. Self-efficacy potentially determines whether an individual will adapt or not. It also determines the nature of adaptation and the extent to which an individual will adapt to climate change.

Based on the foregoing, we present a conceptual model of the hypothesized relationship between climate change adaptation and perceived self-efficacy. In Figure 1, it is suggested that perceived self-efficacy will lead to adaptation (anticipatory and reactive), which will eventually reduce the risk of coastal dwellers to the impacts of climate change. It is also suggested that the composition of the population and contextual attributes of the geographic region will modify the relationship between climate change adaptation and perceived self-efficacy. In the literature adaptation is seldom disaggregated into anticipatory and reactive. However, this was done in this study, in order to elicit a deeper understanding of the complex nature of climate change adaptation. The conceptual distinction between anticipatory and reactive climate change adaptation is important because it determines which human behavior and responses are successful (adaptive) or unsuccessful (maladaptive).

This paper examines the relationship between perceived self-efficacy and adaptation to climate change among coastal communities in Cambodia. This study hypothesizes that there is a positive relationship between perceived self-efficacy and adaptation to climate change among coastal residents. 


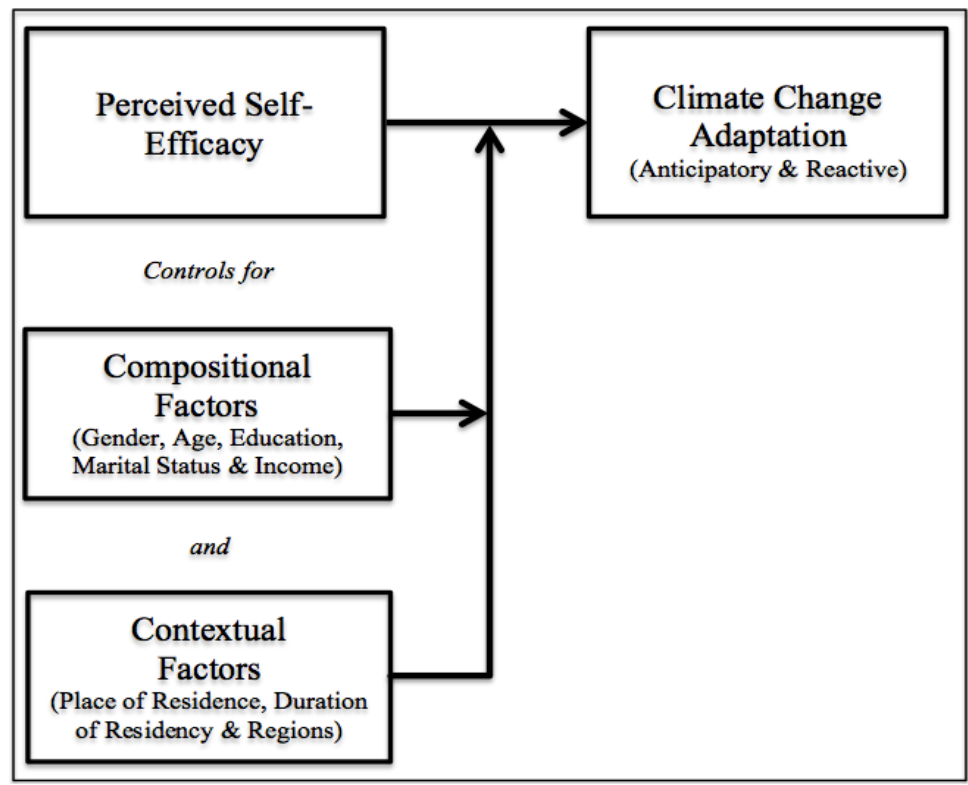

Figure 1. Perceived Self-Efficacy and Climate Change Adaptation (Source: Authors).

\section{Method}

\subsection{Study Context and Data Collection}

This study is part of a larger project called the Indian Ocean World (IOW): the making of the first global economy. IOW focuses on studies of the history, economy, and culture of both lands and people along the Indian Ocean ranging from East Africa through Southeast Asia to China. This study was conducted in coastal Cambodia, mainland Southeast Asia in the Lower Mekong region with an area of $181,035 \mathrm{~km}^{2}$ and lies between parallels of $10^{\circ} \mathrm{N}$ and $15^{\circ} \mathrm{N}$ and meridians of $102^{\circ} \mathrm{E}$ and $108^{\circ}$ E. It is bordered by Laos and Thailand to the north, Gulf of Thailand to the south, Vietnam to the east, and Thailand to the west (Figure 2) [38].
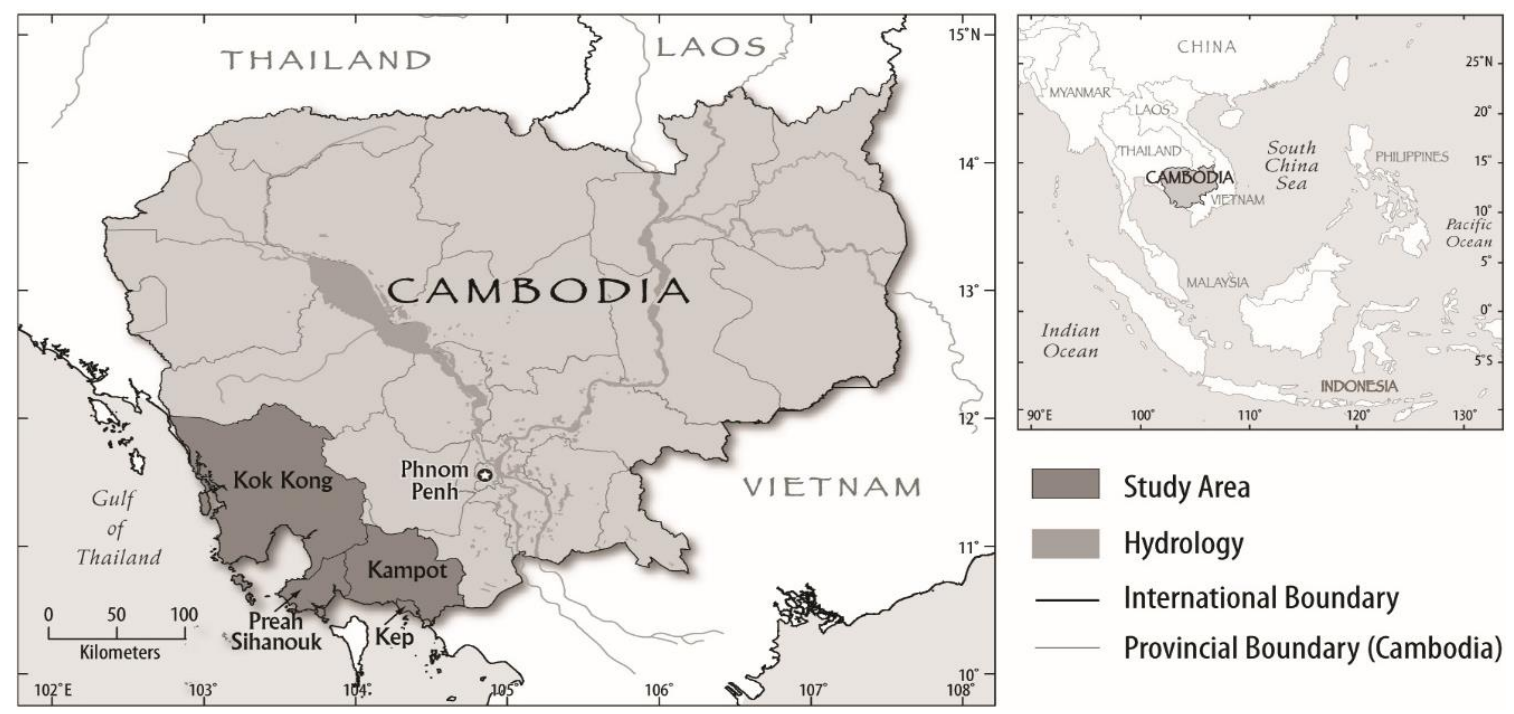

Figure 2. Map of Cambodia and Study Areas (Source: Cartographic Section, Department of Geography, Western University).

Cambodia has tropical climate and is subject to both southeast and northwest monsoons. The southeast monsoon (rainy monsoon), extends from May to October, when the wind direction is from the ocean toward the continental land mass bringing precipitation. The average annual rainfall 
is about $1500 \mathrm{~mm}$, with the heaviest of up to $4000 \mathrm{~mm}$ along the southwest coastline. The northwest monsoon (dry monsoon), extends from November to April, when the wind direction is from Siberia and brings cool and dry air [38]. Administratively, the country is divided into 25 provinces and cities [39]. In 2013, Cambodia had a total population of 14.7 million [40] where over $70 \%$ resided in the rural settings. The population annual growth rate is estimated at $1.83 \%$ and population density is 82 persons per $\mathrm{km}^{2}$ [40]. The sex ratio is 94.2 males per 100 females. It is religiously homogenous with over $95 \%$ Buddhists. The demography has been shaped by history where more than 2 million were killed during the Khmer Rouge from 1975 to 1979. After the genocide period, there were two baby boom periods, $1980-81$ and in the early 1990s. The dependency ratio was 86 persons per 100 workers in 1998 and 61 persons per 100 workers in 2008 since a large proportion of the population are youth of working age [38].

Data for this study were collected from April to September 2013 in four coastal provinces: Kampot, Kep, Kok Kong, and Presh Sihanouk. Data on districts, commune and village were derived from Cambodia 2008 Census database. Using multi-stage random sampling technique, a total of 1823 residents aged 18 years old or older were surveyed from 39 villages in 17 communes in nine districts in four Cambodian coastal provinces. Once the sampling frames were developed, we held meetings with village chiefs to go through the village map and to do random sampling for each village through aerial sampling. The village chiefs were involved in sampling by guiding us through the map.

Ethical approval was obtained from the Western University Non-medical Research Ethics Board in Canada and the National Ethics Committees (NEC) in Cambodia prior to the study. Both oral and written consents were obtained from each participant prior to the interviews. Five skilled interviewers were recruited to conduct the surveys and interviews. A two-day training on study objectives, survey material, sensitivity, and confidentiality of the research was provided to the research assistants prior to the study. Based on the eligibility criteria, participants recruited were 18 years of age or older. A total of 1823 participants (1257 females and 566 males) were interviewed using multi-stage random sampling technique. Double data entry was done using Epi Data 3.1 to minimize non-sampling bias.

\subsection{Measure}

\subsubsection{Outcome Variables}

There are two main outcome variables: anticipatory and reactive adaptation. Anticipatory adaptation is an additive measure, which captures responses on the following statements: "Does your household currently have a plan for what to do to protect yourself and family in the event of extreme impacts of climate change?" (No = 0 , Yes $=1)$ and "Does your household have emergency kits that include items such as flashlight and batteries, non-perishable food, drinking water, and other essential things that can last people for at least three days in case of extreme events associated with climate change?" (No $=0$, Yes $=1)$. The additive nature of this outcome variable makes the anticipatory adaptation an ordered variable ranging from 0 to 2 , where 0 is low, 1 is medium, and 2 is high. Reactive adaptation variable was derived from the following questions "Did your household make any changes because of any previous climate change-related impacts such as flood events or storm surges?" ( $\mathrm{No}=0$, Yes $=1$ ).

\subsubsection{Predictor Variables}

The main predictor variable is perceived self-efficacy, which is an additive scale derived from five variables - perceived self-efficacy based on knowledge on adaptation, confidence in personal abilities, personal preparation, potential consequences of climate change if not prepared, and the real danger of climate change impact. This variable is ordered and ranges from 1 (low) to 5 (high) perceived self-efficacy.

In the literature, both compositional and contextual factors have been shown to vary systematically with actions individuals undertake in their bid to adapt to climate change (see [41]). For this reason, we included compositional variables such as gender, age, education, marital status, 
and household income. Gender was coded as male $=0$ and female $=1$. Age was categorized into six groups: 18-24, 25-34, 35-44, 45-54, 55-64, and 65+ years. Highest level of educational attainment was coded as follows: no education $=0$, primary $=1$, secondary $=2$, and higher $=3$. Marital status was single $=0$ and non-single $=1$. Household income was divided into two categories $\leq$ USD100/month $=0$ and $>$ USD100/month $=1$.

Contextual variables included place of residence (urban $=0$ vs. rural $=1$ ), duration of residence $(<5$ years $=1,6-10$ years $=2,11-16$ years $=3$ and $16+$ years $=4)$ and regions $($ Kampot $=1$, Kep $=2$, Presh Sihanouk $=3$ and Kok Kong = 4).

\subsection{Data Analysis}

Using STATA version 13, the analyses consisted of three parts-Pearson Chi-square and Cramer's V statistics, bivariate and multivariate logistic regression analyses. Pearson Chi-square was used to analyze categorical data (e.g., age groups, gender, and place of residence) and Cramer's V was used as post-test to determine strengths of association after chi-square has determined significance. Pearson Chi-square tests were used to determine whether the observed differences in adaptation with perceived self-efficacy, compositional factors and contextual factors were independent $(\alpha \leq 0.05)$. The measures of association are presented in Table 1 . The results on anticipatory and reactive adaptation are shown in Table 2. Cramer's V, based on Pearson's Chi-square statistic, is used to measure the strength of association between one nominal variable and either another nominal variable, or with an ordinal variable. There is no restriction on the number of categories each variable can have. The Cramer's V statistic values range from 0 to +1 with 0.3 or above considered as strong association [42].

Table 1. Descriptive Statistics of Anticipatory Adaptation to Climate Change reported by individuals in Coastal Cambodia $(n=1823)$.

\begin{tabular}{|c|c|c|c|c|}
\hline \multirow{2}{*}{ Predictor Variables } & \multicolumn{4}{|c|}{ Anticipatory Adaptation } \\
\hline & Low (\%) & Medium (\%) & High (\%) & Pearson's $\chi^{2}(d f)$ \\
\hline \multicolumn{5}{|l|}{ Perceived Self-Efficacy } \\
\hline \multicolumn{5}{|l|}{ Perceived Self-Efficacy } \\
\hline 1 & 0.39 & 0.29 & 0.14 & $\chi^{2}(1)=227.11 \operatorname{Pr}=0.000$ \\
\hline 2 & 4.01 & 1.45 & 1.70 & Cramér's V = 0.25 \\
\hline 3 & 24.45 & 21.22 & 17.42 & \\
\hline 4 & 38.55 & 28.20 & 11.19 & \\
\hline 5 & 32.60 & 48.84 & 69.55 & \\
\hline \multicolumn{5}{|l|}{ Compositional Factor } \\
\hline \multicolumn{5}{|l|}{ Gender } \\
\hline Male & 28.85 & 39.53 & 31.05 & $\chi^{2}(1)=14.3 \operatorname{Pr}=0.001$ \\
\hline Female & 71.15 & 60.47 & 68.95 & Cramér's V = 0.08 \\
\hline \multicolumn{5}{|l|}{ Age } \\
\hline $18-24$ & 10.87 & 7.56 & 8.50 & $\chi^{2}(1)=10.49 \operatorname{Pr}=0.39$ \\
\hline $25-34$ & 21.47 & 25.87 & 23.80 & Cramér's V = 0.05 \\
\hline $35-44$ & 19.28 & 21.22 & 19.41 & \\
\hline $45-54$ & 22.77 & 21.80 & 21.39 & \\
\hline $55-64$ & 15.65 & 16.86 & 16.57 & \\
\hline $65+$ & 9.96 & 6.69 & 10.34 & \\
\hline \multicolumn{5}{|l|}{ Education } \\
\hline No Education & 24.32 & 17.15 & 16.57 & $\chi^{2}(1)=23.72 \operatorname{Pr}=0.001$ \\
\hline Primary Education & 48.12 & 48.26 & 53.54 & Cramér's V = 0.08 \\
\hline Secondary Education & 15.91 & 21.22 & 20.25 & \\
\hline $\begin{array}{l}\text { Higher Education } \\
\text { Marital Status }\end{array}$ & 11.64 & 13.37 & 9.63 & \\
\hline
\end{tabular}




\begin{tabular}{ccccc}
\hline $\begin{array}{c}\text { Single } \\
\text { Non-Single } \\
\text { Income }\end{array}$ & $\begin{array}{c}6.73 \\
93.27\end{array}$ & $\begin{array}{c}6.10 \\
93.90\end{array}$ & $\begin{array}{c}4.96 \\
95.04\end{array}$ & $\begin{array}{c}\chi^{2}(1)=2.09 \mathrm{Pr}=0.35 \\
\text { Cramér's V }=0.03\end{array}$ \\
$\begin{array}{c}\text { <USD100/month } \\
\text { >USD100/month }\end{array}$ & 18.89 & 9.88 & 15.44 & $\chi^{2}(1)=14.61 \mathrm{Pr}=0.001$ \\
Contextual Factor & & 90.12 & 84.56 & Cramér's V $=0.09$ \\
Place of Residence & & & & \\
Urban & 28.33 & 29.94 & 27.90 & $\chi^{2}(1)=0.48 \mathrm{Pr}=0.78$ \\
$\quad$ Rural & 71.67 & 70.06 & 72.10 & Cramér's V $=0.02$ \\
$\begin{array}{c}\text { Duration of Residence } \\
\text { 5 Years }\end{array}$ & 12.55 & 8.43 & 8.92 & $\chi^{2}(1)=16.79 \mathrm{Pr}=0.01$ \\
6-10 Years & 4.66 & 8.14 & 4.96 & Cramér's V $=0.07$ \\
11-15 Years & 6.86 & 9.59 & 6.37 & \\
16+ Years & 75.94 & 73.84 & 79.75 & \\
Regions & & & & \\
Kampot & 29.37 & 31.98 & 25.92 & $\chi^{2}(1)=21.02 \mathrm{Pr}=0.002$ \\
Kep & 18.24 & 15.41 & 13.60 & Cramér's V $=0.08$ \\
Presh Sihanouk & 33.25 & 30.23 & 32.72 & \\
Kok Kong & 19.15 & 22.38 & 27.76 & \\
\hline
\end{tabular}

Response to Anticipatory Adaptation was (Low $=42.40 \%$, Medium $=18.87 \%$, High $=38.73 \%$ ).

Table 2. Descriptive Statistics of Reactive Adaptation to Climate Change in Coastal Cambodia $(n=1823)$.

\begin{tabular}{|c|c|c|c|}
\hline \multirow[b]{2}{*}{ Predictor Variables } & \multicolumn{3}{|c|}{ Reactive Adaptation } \\
\hline & Yes (\%) & No $(\%)$ & Pearson's $\chi^{2}(d f)$ \\
\hline \multicolumn{4}{|l|}{ Perceived Self-Efficacy } \\
\hline \multicolumn{4}{|l|}{ Perceived Self-Efficacy } \\
\hline 1 & 0.11 & 0.50 & $\chi^{2}(1)=427.96 \operatorname{Pr}=0.000$ \\
\hline 2 & 0.32 & 5.11 & Cramér's V = 0.49 \\
\hline 3 & 10.27 & 32.67 & \\
\hline 4 & 15.14 & 36.78 & \\
\hline 5 & 74.16 & 24.94 & \\
\hline \multirow{2}{*}{\multicolumn{4}{|c|}{$\begin{array}{c}\text { Compositional Factor } \\
\text { Gender }\end{array}$}} \\
\hline & & & \\
\hline Male & 29.08 & 33.42 & $\chi^{2}(1)=3.76 \operatorname{Pr}=0.05$ \\
\hline Female & 70.92 & 66.58 & Cramér's V = 0.05 \\
\hline \multicolumn{4}{|l|}{ Age } \\
\hline $18-24$ & 9.19 & 9.73 & $\chi^{2}(1)=5.37 \operatorname{Pr}=0.37$ \\
\hline $25-34$ & 22.49 & 24.06 & Cramér's V = 0.05 \\
\hline $35-44$ & 20.54 & 19.58 & \\
\hline $45-54$ & 21.41 & 22.19 & \\
\hline $55-64$ & 15.78 & 16.83 & \\
\hline $65+$ & 10.59 & 7.61 & \\
\hline \multicolumn{4}{|l|}{ Education } \\
\hline No Education & 18.27 & 20.45 & $\chi^{2}(1)=6.89 \operatorname{Pr}=0.07$ \\
\hline Primary Education & 52.65 & 48.63 & Cramér's V = 0.06 \\
\hline Secondary Education & 19.24 & 17.83 & \\
\hline Higher Education & 9.84 & 13.09 & \\
\hline \multicolumn{4}{|l|}{ Marital Status } \\
\hline Single & 5.73 & 6.48 & $\chi^{2}(1)=0.43 \operatorname{Pr}=0.51$ \\
\hline Non-Single & 94.27 & 93.52 & Cramér's V = 0.02 \\
\hline Household Income & & & \\
\hline
\end{tabular}




\begin{tabular}{cccc}
\hline $\begin{array}{c}\text { <USD100/month } \\
\text { >USD100/month }\end{array}$ & 14.92 & 15.59 & $\chi^{2}(1)=0.15 \mathrm{Pr}=0.70$ \\
Cramér's V $=0.00$ \\
$\begin{array}{c}\text { Contextual Factor } \\
\text { Place of Residence }\end{array}$ & & 84.41 & \\
Urban & 28.11 & 26.68 & $\chi^{2}(1)=0.06 \mathrm{Pr}=0.79$ \\
Cramér's V $=0.00$ \\
$\begin{array}{c}\text { Rural } \\
\text { Duration of Residence }\end{array}$ & 71.89 & 71.32 & \\
5 Years & 7.35 & 13.97 & $\chi^{2}(1)=21.84 \mathrm{Pr}=0.00$ \\
6-10 Years & 4.97 & 5.99 & Cramér's V $=0.11$ \\
11-15 Years & 7.14 & 6.73 & \\
16+ Years & 80.54 & 73.32 & \\
Regions & & & \\
Kampot & 22.49 & 34.66 & $\chi^{2}(1)=41.50 \mathrm{Pr}=0.00$ \\
Kep & 14.81 & 16.33 & Cramér's V $=0.15$ \\
Presh Sihanouk & 34.80 & 30.30 & \\
Kok Kong & 28.00 & 18.70 & \\
\hline Response to Reactive Adaptation was $($ Yes $=53.56 \%$, No $=46.44 \%)$.
\end{tabular}

In the bivariate (Table 3) and multivariate analyses (Tables 4 and 5), two different analyses were performed, ordered logistic regression and logistic regression for anticipatory and reactive adaptation outcome variables, respectively in order to accommodate the nature of the outcome variables. Ordinal categories of anticipatory adaptation-low, medium, and high were coded as 0,1 , and 2. The coefficients estimated in the models indicate the likelihood of being more able to adapt (in this case, moving into a higher category of adaptation). Also, reactive adaptation was coded 0 (No) and 1 (Yes). The results of both ordered logistic and logistic regression were reported as Odds Ratios (OR). OR that is greater than 1 implies more likelihood of reporting higher levels of adaptation.

Table 3. Bivariate Ordered Logistic Regression Analysis on Anticipatory and Reactive Adaptation to Climate Change in Coastal Cambodia $(n=1823)$.

\begin{tabular}{ccccc}
\hline \multirow{2}{*}{ Predictor Variables } & \multicolumn{3}{c}{ Anticipatory Adaptation } & \multicolumn{3}{c}{ Reactive Adaptation } \\
\cline { 2 - 5 } & OR & SE & OR & SE \\
\hline Perceived Self-Efficacy & & & & \\
Perceived Self-Efficacy & & & & \\
Low & 1.00 & 1.00 & 1.00 & 1.00 \\
High & $1.75^{* * *}$ & 0.09 & $3.47^{* * *}$ & 0.24 \\
Compositional Factor & & & & \\
Gender & & & & \\
Male & 1.00 & 1.00 & 1.00 & 1.00 \\
Female & 0.97 & 0.09 & 1.22 & 0.13 \\
Age & & & & \\
18-24 & 1.00 & 1.00 & 1.00 & 1.00 \\
25-34 & 1.36 & 0.23 & 0.99 & 0.18 \\
35-44 & 1.26 & 0.22 & 1.11 & 0.21 \\
45-54 & 1.19 & 0.21 & 1.02 & 0.19 \\
55-64 & 1.31 & 0.24 & 0.99 & 0.19 \\
65+ & 1.28 & 0.26 & 1.47 & 0.33 \\
Education & & & & \\
No Education & 1.00 & 1.00 & 1.00 & 1.00 \\
Primary Education & $1.54^{* * *}$ & 0.18 & 1.21 & 0.16 \\
Secondary Education & $1.71^{* * *}$ & 0.24 & 1.21 & 0.19 \\
Higher Education & 1.22 & 0.19 & 0.84 & 0.15 \\
Marital Status & & & & \\
\hline & & & & \\
\hline
\end{tabular}




\begin{tabular}{|c|c|c|c|c|}
\hline Single & 1.00 & 1.00 & 1.00 & 1.00 \\
\hline Non-Single & 1.30 & 0.24 & 1.14 & 0.22 \\
\hline \multicolumn{5}{|l|}{ Household Income } \\
\hline <USD100/month & 1.00 & 1.00 & 1.00 & 1.00 \\
\hline >USD100/month & $1.28 *$ & 0.16 & 1.05 & 0.14 \\
\hline \multicolumn{5}{|l|}{ Contextual Factor } \\
\hline \multicolumn{5}{|l|}{ Place of Residence } \\
\hline Urban & 1.00 & 1.00 & 1.00 & 1.00 \\
\hline Rural & 1.02 & 0.09 & 1.03 & 0.11 \\
\hline \multicolumn{5}{|l|}{ Duration of Residence } \\
\hline$<5$ Years & 1.00 & 1.00 & 1.00 & 1.00 \\
\hline $6+$ Years & $1.10 *$ & 0.05 & $1.24^{* * *}$ & 0.06 \\
\hline \multicolumn{5}{|l|}{ Regions } \\
\hline Kampot & 1.00 & 1.00 & 1.00 & 1.00 \\
\hline Other Coastal Provinces & $1.01^{* * *}$ & 0.01 & $1.03^{* * *}$ & 0.01 \\
\hline
\end{tabular}

Table 4. Multivariate Ordered Logistic Regression Analysis on Anticipatory Adaptation to Climate Change in Coastal Cambodia $(n=1823)$.

\begin{tabular}{|c|c|c|c|c|c|c|}
\hline \multirow{2}{*}{ Predictor Variables } & \multicolumn{2}{|c|}{ Perceived Self-Efficacy } & \multicolumn{2}{|c|}{ Compositional Factor } & \multicolumn{2}{|c|}{ Contextual Factor } \\
\hline & OR & SE & OR & SE & OR & SE \\
\hline \multicolumn{7}{|l|}{ Perceived Self-Efficacy } \\
\hline \multicolumn{7}{|l|}{ Perceived Self-Efficacy } \\
\hline Low & 1.00 & 1.00 & 1.00 & 1.00 & 1.00 & 1.00 \\
\hline High & $1.74^{* * *}$ & 0.09 & $1.75^{* * *}$ & 0.09 & $1.74^{* * *}$ & 0.09 \\
\hline \multicolumn{7}{|l|}{ Compositional Factor } \\
\hline \multicolumn{7}{|l|}{ Gender } \\
\hline Male & & & 1.00 & 1.00 & 1.00 & 1.00 \\
\hline Female & & & 0.93 & 0.09 & 0.92 & 0.09 \\
\hline \multicolumn{7}{|l|}{ Age } \\
\hline $18-24$ & & & 1.00 & 1.00 & 1.00 & 1.00 \\
\hline $25-34$ & & & 1.30 & 0.25 & 1.29 & 0.25 \\
\hline $35-44$ & & & 1.17 & 0.24 & 1.15 & 0.23 \\
\hline $45-54$ & & & 1.19 & 0.24 & 1.15 & 0.23 \\
\hline $55-64$ & & & 1.29 & 0.27 & 1.23 & 0.26 \\
\hline $65+$ & & & 1.53 & 0.37 & 1.46 & 0.35 \\
\hline \multicolumn{7}{|l|}{ Education } \\
\hline No Education & & & 1.00 & 1.00 & 1.00 & 1.00 \\
\hline Primary Education & & & $1.61^{* * *}$ & 0.21 & $1.64^{* * *}$ & 0.21 \\
\hline Secondary Education & & & $2.02^{* * *}$ & 0.32 & $2.06^{* * *}$ & 0.32 \\
\hline Higher Education & & & $1.65^{* * *}$ & 0.29 & $1.71^{* * *}$ & 0.31 \\
\hline \multicolumn{7}{|l|}{ Marital Status } \\
\hline Single & & & 1.00 & 1.00 & 1.00 & 1.00 \\
\hline Non-Single & & & 1.06 & 0.23 & 1.09 & 0.24 \\
\hline \multicolumn{7}{|l|}{ Household Income } \\
\hline$<$ USD100/month & & & 1.00 & 1.00 & 1.00 & 1.00 \\
\hline >USD100/month & & & 1.21 & 0.15 & 1.21 & 0.15 \\
\hline \multicolumn{7}{|l|}{ Contextual Factor } \\
\hline \multicolumn{7}{|l|}{ Place of Residence } \\
\hline Urban & & & & & 1.00 & 1.00 \\
\hline Rural & & & & & 1.12 & 0.22 \\
\hline \multicolumn{7}{|l|}{ Duration of Residence } \\
\hline$<5$ Years & & & & & 1.00 & 1.00 \\
\hline $6+$ Years & & & & & $1.09 *$ & 0.05 \\
\hline \multicolumn{7}{|l|}{ Regions } \\
\hline Kampot & & & & & 1.00 & 1.00 \\
\hline Others Coastal Provinces & & & & & $1.01 *$ & 0.01 \\
\hline Log Likelihood & -1839.83 & & -1825.21 & & -1821.53 & \\
\hline \multicolumn{7}{|l|}{ Variance of Random Effect } \\
\hline Level 2 (Commune) Variance & 0.05 & & $0.06^{* * *}$ & & $0.05^{*}$ & \\
\hline
\end{tabular}




\begin{tabular}{cccc}
\hline Level 3 (District) Variance & 0.04 & 0.01 & 0.01 \\
$p$ (Same District, Different Communes) & 0.01 & 0.02 & 0.03 \\
$p$ (Same Commune, Same Districts) & 0.06 & 0.03 & 0.04 \\
\hline
\end{tabular}

${ }^{*} p<0.05 \&{ }^{* * *} p<0.001, \mathrm{OR}=$ Odds Ratio, SE = Standard Errors.

Table 5. Multivariate Logistic Regression Analysis on Reactive Adaptation to Climate Change in Coastal Cambodia $(n=1823)$.

\begin{tabular}{|c|c|c|c|c|c|c|}
\hline \multirow{2}{*}{ Predictor Variables } & \multicolumn{2}{|c|}{ Perceived Self-Efficacy } & \multicolumn{2}{|c|}{ Compositional Factor } & \multicolumn{2}{|c|}{ Contextual Factor } \\
\hline & OR & SE & OR & SE & OR & $\mathrm{SE}$ \\
\hline \multicolumn{7}{|l|}{ Perceived Self-Efficacy } \\
\hline \multicolumn{7}{|l|}{ Perceived Self-Efficacy } \\
\hline Low & 1.00 & 1.00 & 1.00 & 1.00 & 1.00 & 1.00 \\
\hline High & $3.57^{* * *}$ & 0.26 & $3.69^{* * *}$ & 0.27 & $3.61^{* * *}$ & 0.27 \\
\hline \multicolumn{7}{|l|}{ Compositional Factor } \\
\hline \multicolumn{7}{|l|}{ Gender } \\
\hline Male & & & 1.00 & 1.00 & 1.00 & 1.00 \\
\hline Female & & & 1.02 & 0.12 & 1.01 & 0.13 \\
\hline \multicolumn{7}{|l|}{ Age } \\
\hline $18-24$ & & & 1.00 & 1.00 & 1.00 & 1.00 \\
\hline $25-34$ & & & 0.81 & 0.19 & 0.80 & 0.19 \\
\hline $35-44$ & & & 0.94 & 0.23 & 0.91 & 0.23 \\
\hline $45-54$ & & & 0.88 & 0.21 & 0.81 & 0.20 \\
\hline $55-64$ & & & 0.80 & 0.21 & 0.70 & 0.18 \\
\hline $65+$ & & & 1.37 & 0.41 & 1.25 & 0.37 \\
\hline \multicolumn{7}{|l|}{ Education } \\
\hline No Education & & & 1.00 & 1.00 & 1.00 & 1.00 \\
\hline Primary Education & & & $1.41^{* *}$ & 0.22 & $1.47^{* *}$ & 0.23 \\
\hline Secondary Education & & & $1.88^{* * *}$ & 0.37 & $1.98^{* * *}$ & 0.39 \\
\hline Higher Education & & & $1.54^{*}$ & 0.34 & $1.63^{*}$ & 0.36 \\
\hline \multicolumn{7}{|l|}{ Marital Status } \\
\hline Single & & & 1.00 & 1.00 & 1.00 & 1.00 \\
\hline Non-Single & & & 0.72 & 0.20 & 0.77 & 0.21 \\
\hline \multicolumn{7}{|l|}{ Household Income } \\
\hline$<\mathrm{USD} 100 /$ month & & & 1.00 & 1.00 & 1.00 & 1.00 \\
\hline >USD100/month & & & 0.99 & 0.16 & 1.00 & 0.16 \\
\hline \multicolumn{7}{|l|}{ Contextual Factor } \\
\hline \multicolumn{7}{|l|}{ Place of Residence } \\
\hline Urban & & & & & 1.00 & 1.00 \\
\hline Rural & & & & & 1.41 & 0.39 \\
\hline \multicolumn{7}{|l|}{ Duration of Residence } \\
\hline$<5$ Years & & & & & 1.00 & 1.00 \\
\hline $6+$ Years & & & & & $1.22^{* * *}$ & 0.07 \\
\hline \multicolumn{7}{|l|}{ Regions } \\
\hline Kampot & & & & & 1.00 & 1.00 \\
\hline Others Coastal Provinces & & & & & $1.03^{* * *}$ & 0.01 \\
\hline Log Likelihood & -974.34 & & -964.47 & & -953.43 & \\
\hline \multicolumn{7}{|l|}{ Variance of Random Effect } \\
\hline Level 2 (Commune) Variance & 0.14 & & $0.23 * * *$ & & $0.07^{*}$ & \\
\hline Level 3 (District) Variance & 0.15 & & $0.25^{* * *}$ & & 0.01 & \\
\hline$p$ (Same District, Different Communes) & 0.04 & & 0.06 & & 0.01 & \\
\hline$p$ (Same Commune, Same Districts) & 0.18 & & 0.30 & & 0.08 & \\
\hline
\end{tabular}

${ }^{*} p<0.05,{ }^{* *} p<0.01 \&{ }^{* * *} p<0.001, \mathrm{OR}=$ Odds Ratio, SE = Standard Errors.

In the multivariate analyses (Tables 4 and 5), predictor variables were clustered into three distinct models. In Model I, the main predictor variable is perceived self-efficacy. Model II accounts for compositional factors such as gender, age, education, marital status, and income. In Model III, we controlled for contextual factors such as place of residence, duration of residency, and region.

It is worth noting the hierarchical nature of the data, whereby individuals are nested in commune, which in turn are nested in a district. Individuals in the same commune and district may have similar characteristics such as environmental exposure and other sociocultural attributes. If ignored, this will violate the assumption of independence in conventional models. Therefore, unless some allowance is made, these models will no longer be valid. In order to account for this, we 
specified a three-level random intercept model with a respondent $i$, nested in commune $j$, which is nested in the district $k$.

Various types of intra-class correlations can be derived for the response of two participants. For instance, for the same district $k$ but different commune $j$ and $j^{\prime}$, we obtain

$$
\rho(\text { district })=v_{k} /\left(\omega_{j k}+v_{k}+\frac{\pi^{2}}{3}\right)
$$

whereas for the same commune $j$ and the same district $k$, we get

$$
\rho(\text { commune, district })=\omega_{j k}+v_{k} /\left(\omega_{j k}+v_{k}+\frac{\pi^{2}}{3}\right)
$$

where $\omega_{j k}$ (omega $j k$ ) is the estimated commune level variance, $v_{k}$ (upsilon $k$ ) is the estimated district level variance and $\frac{\pi^{2}}{3}$ is the variance of a standard logistic distribution. In a three-level model, if $\omega_{j k}>0$ and $v_{k}>0$, it follows that $\rho$ (commune, district) $>\rho$ (district) because individuals of a given commune are more similar than individuals from the same district but different communes. The GLLAMM (Generalized Linear Latent and Mixed Models) command $[43,44]$ was executed in STATA version 13 for the estimation of both the ordered logistic and logistic regression analysis.

\section{Results}

\subsection{Univariate Analysis}

The chi-square statistic strongly rejects the hypothesis that perceived self-efficacy and adaptations are independent $(p<0.001)$ and the Cramér's V statistic is 0.25 for anticipatory adaptation and 0.49 for reactive adaptation, respectively (Tables 1 and 2). The chi-square statistics for gender, education, and income firmly rejected the hypothesis they are independent with anticipatory adaptation. However, Cramér's V statistic values were less than 0.3 , which is a cut off point for a strong measure [42] (Table 1). The chi-square statistics for contextual factors except place of residence are associated with anticipatory and reactive adaptation (Tables 1 and 2).

\subsection{Bivariate Analysis}

Table 3 illustrates the results of bivariate ordered logistic regression on anticipatory adaptation. The results suggest that those who reported higher categories of perceived self-efficacy were more likely $(\mathrm{OR}=1.75, p<0.001)$ to report anticipatory adaptation. Likewise, those who completed primary and secondary education were more likely $(\mathrm{OR}=1.54, p<0.001$ and $\mathrm{OR}=1.71, p<0.001$, respectively) to report higher anticipatory adaptation compared with those who did not have any formal education. Participants who reported household incomes of more than USD100 a month were more likely $(\mathrm{OR}=1.28, p<0.05)$ to report higher anticipatory adaptation. Those who had stayed in their neighborhood for six or more years were more likely $(\mathrm{OR}=1.10, p<0.05)$ to report higher anticipatory adaptation. Finally compared with those who lived in Kampot province, those who lived in other coastal provinces were more likely ( $\mathrm{OR}=1.01, p<0.001)$ to report anticipatory adaptation (Table 3 ).

Table 3 also provides the results of bivariate logistic regression on reactive adaptation. The results suggest that those who self-reported high perceived self-efficacy were more likely $(\mathrm{OR}=3.47$, $p<0.001)$ to report reactive adaptation. Also, those who had six or more years length of stay were more likely $(\mathrm{OR}=1.24, p<0.001)$ to report reactive adaptation. Finally, those who resided in other coastal provinces were more likely $(\mathrm{OR}=1.03, p<0.001)$ to report reactive adaptation compared with those who lived in Kampot province (Table 3).

\subsection{Multivariate Analysis}

Results of the multivariate ordered logistic regression analysis are presented for anticipatory adaptation in Table 4. Model I suggests that those who reported high perceived self-efficacy were more likely $(\mathrm{OR}=1.74, p<0.001)$ to report higher order of anticipatory adaptation. Perceived self-efficacy maintained a positive relationship with anticipatory adaptation even after controlling for 
compositional factors in Model II. Those who had education at any level were more likely to report better anticipatory adaptation than their counterparts without any formal education (Table 4). After controlling for contextual factors in Model III, the relationship of both perceived self-efficacy and education with anticipatory adaptation remained robust. Those who reported high perceived self-efficacy and those who completed any level of education were more likely to report higher orders of anticipatory adaptation (Table 4). Those who had resided in their current residence for six or more years were more likely $(\mathrm{OR}=1.09, p<0.05)$ to report higher order of anticipatory adaptation compared with those who had lived in the neighborhood for a shorter period. Where people live matters to their adaptation. The results indicated that region was a significant predictor of anticipatory adaptation among coastal residents in Cambodia. Compared with those who lived in Kamport province, where it is the most agriculture dependent and climate sensitive, those who lived in the other three coastal provinces reported more likely to report better adaptation to climate change.

Results from multivariate logistic regression analysis on reactive adaptation are presented in Table 5. In Model I, those with high perceived self-efficacy were more likely (OR $=3.57, p<0.001)$ to report reactive adaptation. After controlling for compositional factors in Model II, perceived self-efficacy remained a significant predictor of reactive adaptation. Those who completed formal education at any level were more likely to report reactive adaptation compared with those who did not have formal education (Table 5). In Model III, the direction and magnitude of both perceived self-efficacy and education remain robust. Duration of residence was a significant predictor of reactive adaptation $(\mathrm{OR}=1.22, p<0.001)$. The findings also suggest that there are regional differences in terms of reactive adaptation to climate change.

Results from intra-class correlation for anticipatory adaptation showed that $\rho$ (district) (Model III) was statistically significant at $\alpha$-level of 0.05 (Table 4). Likewise, the intra-class correlation for reactive adaptation illustrated that $\rho$ (district) (Model III) was statistically significant at the 0.05 level (Table 5). The intra-class correlation points out that there is a significant amount of clustering, the consequence of which could bias our parameter estimates, which is corrected by using pseudo multilevel modeling in the analysis.

\section{Discussion}

This paper examines the relationship between perceived self-efficacy and climate change adaptation among coastal communities in Cambodia. The findings suggest that perceived self-efficacy plays an important role in predicting both anticipatory and reactive adaptation to climate change. This finding is corroborated by Jones and Boyd (2011) who found a strong influence of cognitive and adaptation behavior in Western Nepal [45]. As expected, those who reported high self-efficacy were more likely to report better adaptive strategies. The relationship remained robust even after controlling for compositional and contextual factors in the analysis. This finding speaks directly to the theoretical conceptualization of self-efficacy and adaptation. Furthermore, works on the negative impacts of climate change have pointed out that whether or not an individual will take proactive steps hinges on how they perceive their own ability to enact these steps $[17,29,46]$.

Despite the fact that the literature suggests significant differences of adaptation behavior across compositional factors such as socio-economic and demographics [47], the findings of this study indicated otherwise. Apart from education, all other socio-economic and demographic factors were not statistically significant in the analysis, not even at the bivariate level. This potentially suggests that along coastal Cambodia, socio-demographic factors may not be the main drivers of adaptation to climate change at the individual and household levels. It is worth noting in the final models that all of the significant predictors except education had a greater magnitude in reactive adaptation than in anticipatory adaptation. Education, on the other hand, had a relatively greater magnitude in anticipatory than in reactive adaptation. This suggests that education is crucial when it comes to anticipatory adaptation, which involves the ability to foresee potential advance events and plan ahead of time. The inconsistency of our findings with the literature may be attributed to the way the literature seldom segregates anticipatory and reactive adaptation for quantitative analyses. Nevertheless, the emergence of education as a significant predictor of adaptive capacity is consistent 
with Deressa et al., (2009) who reported a positive relationship between education and adaptation to climate change among farmers in the Nile Basin of Ethiopia. Indeed, findings elsewhere highlight the importance of education in climate change adaptation $[48,49]$, and the need to incorporate education as a climate change strategy policy.

Contextual factors (duration of residence and regions) show significant independent effects on both types of adaptation to climate change. As expected, longer duration of residence by participants is positively associated with better adaptation likely due to their previous experiences with climate hazards in the same community. The regional differences in climate change adaptation suggest spatial variation and significance in adaptation to climate change. Given that adaptation will be mediated by spatial heterogeneity in climate and climate change [50], the regional differences observed in this study could inform context-specific policies on adaptation. For instance, it could potentially serve as basis for developing different coping strategies at the local level in response to local adaptation needs. Beyond the local level, anticipatory and reactive adaptation systematically varied by commune suggest that a nuanced understanding of climate change adaptation is cross-scalar. This finding is consistent with the literature. Previous research demonstrates that adaptation is a more complex and iterative process concerning individuals, institutions, and multilevel government groups (see [5,36,51-55]). For this reason, multilevel studies on climate change adaptation may be the way forward for future research.

\section{Conclusions}

This paper set out to assess the relationship between perceived self-efficacy of residents in coastal communities in Cambodia and climate change adaptation. In order to obtain a deeper understanding of the complex nature of climate change adaptation, it was distinguished into anticipatory and reactive. Although education, duration of residency, and regions were the main determinants of anticipatory and reactive climate change adaptation, the effect sizes (odds ratios) were different. To varying degrees of statistical significance and practical importance, perceived self-efficacy was a predictor of both forms of adaptation. Perceived self-efficacy had the highest effect size on reactive adaptation whereas education had the highest effect size on anticipatory adaptation. This signifies the importance of individual perception of their efficacy in adaptation behavior hence suggesting the need to empower individuals at the local level to have better adaptation behavior. Mainstreaming climate change impacts, raising awareness on adaptation strategies through both formal and non-formal education at the community level is imperative. Due to observed regional differences in climate adaptation in this study, contextual factors should be an integral component of adaptation planning and strategy in all communes and coastal provinces. The foregoing findings are extremely important as a guide to policy dialogue on climate change-related work in general and for the Cambodian National Adaptation Program of Action (NAPA) on Climate Change.

Acknowledgments: We, the authors, acknowledge research funding from the Social Sciences and Humanities Research Council of Canada on the project entitled "the Indian Ocean World: The Making of the First Global Economy in the Context of Human Environment Interaction". The funders had no role in study design, data collection and analysis, decision to publish, or preparation of the manuscript. We also wish to express our sincere thanks to Frederick Ato Armah of the Department of Geography, Western University, London, ON, Canada and Eric Y. Tenkorang of the Department of Sociology, Memorial University, St John's, NL, Canada for technical consultancy and reading through the original manuscript.

Author Contributions: Mengieng Ung and Isaac Luginaah were involved in the conception and design of the study. Mengieng Ung was involved in data collection and processing. Mengieng Ung and Isaac Luginaah were involved in data analysis and interpretation. Mengieng Ung, Isaac Luginaah, Ratana Chuenpagdee, and Gwyn Campbell were involved in drafting and critically revised the article and final approval of the version to be published.

Conflicts of Interest: The authors declare no conflict of interest.

\section{References}


1. Folke, C. Resilience: The emergence of a perspective for social-ecological systems analyses. Glob. Environ. Chang. 2006, 16, 253-267.

2. Smit, B.; Wandel, J. Adaptation, adaptive capacity and vulnerability. Glob. Environ. Chang. 2006, 16, 282-292.

3. Huang, C.; Vaneckova, P.; Wang, X.; Fitzgerald, G.; Guo, Y.; Tong, S. Constraints and barriers to public health adaptation to climate change: A review of the literature. Am. J. Prev. Med. 2011, 40, 183-190.

4. Adger, W.N. Vulnerability. Glob. Environ. Chang. 2006, 16, 268-281.

5. Adger, W.N.; Dessai, S.; Goulden, M.; Hulme, M.; Lorenzoni, I.; Nelson, D.R.; Naess, L.O.; Wolf, J.; Wreford, A. Are there social limits to adaptation to climate change? Clim. Chang. 2009, 93, 335-354.

6. Smit, B.; Burton, I.; Klein, R.J.T.; Street, R. The science of adaptation: A framework for assessment. Mitig. Adapt. Strategies Glob. Chang. 1999, 4, 199-213.

7. Smithers, J.; Smit, B. Human adaptation to climatic variability and change. Glob. Environ. Chang. 1997, 7, 129-146.

8. Smit, B.; Pilifosova, O. Adaptation to climate change in the context of sustainable development and equity. Sustain. Dev. 2003, 8, 876-912.

9. Barros, V.R.; Field, C.B.; Dokken, D.J.; Mastrandrea, M.D.; Mach, K.J.; Bilir, T.E.; Chatterjee, M.; Ebi, K.L.; Estrada, Y.O.; Genova, R.C.; et al. Climate Change 2014: Impacts, Adaptation, and Vulnerability. Part B: Regional Aspects; Cambridge University Press: Cambridge, UK, 2014.

10. Leary, N.; Adejuwon, J.; Barros, V.; Burton, I.; Kulkarni, J.; Lasco, R. Climate Change and Adaptation; Routledge: London, UK.

11. McCarthy, J.J.; Canziani, O.F.; Leary, N.A.; Dokken, D.J.; White, K.S. Climate Change 2001: Impacts, Adaptation, and Vulnerability. Cambridge University Press: Cambridge, UK, 2001.

12. Tol, R.S.J.; Klein, R.J.T.; Nicholls, R.J. Towards successful adaptation to sea-level rise along Europe's coasts. J. Coast. Res. 2008, 24, 432-442.

13. Smit, B.; Burton, I.; Klein, R.J.T.; Wandel, J. An anatomy of adaptation to climate change and variability. Clim. Chang. 2000, 45, 223-251.

14. Howe, P.D. Hurricane preparedness as anticipatory adaptation: A case study of community businesses. Glob. Environ. Chang. 2011, 21, 711-720.

15. Burton, I.; Diringer, E.; Smith, J. Adaptation to Climate Change: International Policy Options; Pew Center on Global Climate Change: Arlington, VA, USA, 2006.

16. Intergovernmental Panel on Climate Change (IPCC). Climate Change 2007: Synthesis Report; IPCC: Geneva, Switzerland, 2007.

17. Grothmann, T.; Patt, A. Adaptive capacity and human cognition: The process of individual adaptation to climate change. Glob. Environ. Chang. 2005, 15, 199-213.

18. Lorenzoni, I.; Jordan, A.; O’Riordan, T.; Kerry Turner, R.; Hulme, M. A co-evolutionary approach to climate change impact assessment-Part II: A scenario-based case study in East Anglia (UK). Glob. Environ. Chang. 2000, 10, 145-155.

19. Narayan-Parker, D. Measuring Empowerment: Cross-Disciplinary Perspectives; World Bank: Washington, DC, USA, 2005.

20. Reser, J.P.; Swim, J.K. Adapting to and coping with the threat and impacts of climate change. Am. Psychol. 2011, 66, 277-289.

21. Osberghaus, D.; Finkel, E.; Pohl, M. Individual adaptation to climate change: The role of information and perceived risk. Available online: ftp://ftp.zew.de/pub/zew-docs/dp/dp10061.pdf (accessed on 12 June 2015).

22. Dany, V.; Bowen, K.J.; Miller, F. Assessing the institutional capacity to adapt to climate change: A case study in the Cambodian health and water sectors. Clim. Policy 2015, 15, 388-409.

23. Resurreccion, B.P.; Sajor, E.E.; Fajber, E. Climate adaptation in Asia: Knowledge gaps and research issues in South East Asia; Institute for Social and Environmental Transition (ISET): Kathmandu, Nepal, 2008.

24. Mekong River Commission. Flood Situation Report; Mekong River Commission: Phnom Penh, Cambodia, 2011.

25. Ministry of Environment. National Adaptation Programme of Action to Climate Change (NAPA); Ministry of Environment: Phnom Penh, Cambodia, 2006.

26. Moriarty, C.M. Effects of Self-Efficacy and Response Efficacy Messages in Health News: Changing Health Attitudes and Behavioral Intentions. Ph.D. Thesis, University of Illinois at Urbana-Champaign, 
Champaign, IL, USA, 2010.

27. Maiman, L.A.; Becker, M.H. The health belief model: Origins and correlates in psychological theory. Health Educ. Monogr. 1974, 2, 336-353.

28. Rogers, R.W. A protection motivation theory of fear appeals and attitude change1. J. Psychol. 1975, 91, 93114.

29. Rogers, R.W.; Cacioppo, J.T.; Petty, R. Cognitive and physiological processes in fear appeals and attitude change: A revised theory of protection motivation. In Social Psychophysiology: A Sourcebook; The Guilford Press: New, York, NY, USA, 1983; pp. 153-177.

30. Ajzen, I. From intentions to actions: A theory of planned behavior. In Action Control: From Cognition to Behavior; Springer: Berlin, Germany, 1985; pp. 11-39.

31. Bandura, A. A social cognitive perspective on positive psychology. Rev. Psicol. Soc. 2011, 26, 7-20.

32. Bandura, A. Self-Efficacy: The Exercise of Control; Macmillan: London, UK, 1997.

33. Witte, K. Putting the fear back into fear appeals: The extended parallel process model. Commun. Monogr. 1992, 59, 329-349.

34. Witte, K. Fear as motivator, fear as inhibitor: Using the EPPM to explain fear appeal successes and failures. In The Handbook of Communication and Emotion; Andersen, P.A., Guerrero, L.K., Eds.; Academic Press: New York, NY, USA, 1998; pp. 423-450.

35. Bandura, A. Social Foundations of Thought and Action: A Social Cognitive Theory; Prentice Hall: Upper Saddle River, NJ, USA, 1986.

36. Hanson-Easey, S.; Bi, P.; Williams, S. Public Understanding of Climate Change and Adaptation in South Australia; National Climate Change Adaptation Research Facility: Southport, QLD, Canada, 2013.

37. Kellstedt, P.M.; Zahran, S.; Vedlitz, A. Personal efficacy, the information environment, and attitudes toward global warming and climate change in the United States. Risk Anal. 2008, 28, 113-126.

38. Ministry of Planning. General Population Census of Cambodia 2008, Provisional Population Totals National Institute of Statistics; Ministry of Planning: Phnom Penh, Cambodia, 2008.

39. Kunthear, M.; Ponniah, K. Kampong cham's great divide. Phnom Penh Post, 10 January 2014.

40. Ministry of Planning. Ageing and Migration in Cambodia: A CRUMP Series Report; Ministry of Planning: Phnom Penh, Cambodia, 2013.

41. Balbus, J.M.; Malina, C. Identifying vulnerable subpopulations for climate change health effects in the United States. J. Occup. Environ. Med. 2009, 51, 33-37.

42. Cramér, H. Mathematical Methods of Statistics; Princeton University Press: Princeton, NJ, USA, 1999.

43. Bickel, G.; Nord, M.; Price, C.; Hamilton, W.; Cook, J. Guide to Measuring Household Food Security; United States Department of Agriculture: Naches, WA, USA, 2000.

44. Rabe-Hesketh, S.; Skrondal, A.; Pickles, A. Generalized multilevel structural equation modeling. Psychometrika 2004, 69, 167-190.

45. Jones, L.; Boyd, E. Exploring social barriers to adaptation: Insights from Western Nepal. Glob. Environ. Chang. 2011, 21, 1262-1274.

46. Wolf, J.; Lorenzoni, I.; Few, R.; Abrahmson, V.; Raine, R. Conceptual and Practical Barriers to Adaptation: An. Interdisciplinary Analysis of Vulnerability and Response to Heat Waves in the UK. Adapting to Climate Change: Thresholds, Values, Governance; Cambridge University Press: Cambridge, UK, 2009.

47. Deressa, T.T.; Hassan, R.M.; Ringler, C.; Alemu, T.; Yesuf, M. Determinants of farmers' choice of adaptation methods to climate change in the Nile Basin of Ethiopia. Glob. Environ. Chang. 2009, 19, 248-255.

48. Asfaw, A.; Admassie, A. The role of education on the adoption of chemical fertiliser under different socioeconomic environments in Ethiopia. Agric. Econ. 2004, 30, 215-228.

49. Striessnig, E.; Lutz, W.; Patt, A.G. Effects of educational attainment on climate risk vulnerability. Ecol. Soc. 2013, 18, doi:org/10.5751/ES-05252-180116.

50. Ackerly, D.D.; Loarie, S.R.; Cornwell, W.K.; Weiss, S.B.; Hamilton, H.; Branciforte, R.; Kraft, N.J.B. The geography of climate change: Implications for conservation biogeography. Divers. Distrib. 2010, 16, 476-487.

51. Adger, W.N.; Arnell, N.W.; Tompkins, E.L. Successful adaptation to climate change across scales. Glob. Environ. Chang. 2005, 15, 77-86.

52. Kettle, N.P. Coastal Climate Change Adaptation: The Influence of Perceived Risk, Uncertainty, Trust, and Scale. Ph.D. Thesis, University of South Carolina, Columbia, SC, USA, 2012.

53. Root, T.L.; Schneider, S.H. Strategic cyclical scaling: Bridging five orders of magnitude scale gaps in climatic 
and ecological studies. Integr. Assess. 2002, 3, 188-200.

54. Wilbanks, T.J. How scale matters: Some concepts and findings. In Bridging Scales and Knowledge Systems: Concepts and Applications in Ecosystem Assessment; Reid, W.V., Berkes, F., Wilbanks, T.J., Capistrano, D., Eds.; Island Press: Washington, DC, USA, 2006; pp. 21-35.

55. Wilbanks, T.J.; Kates, R.W. Global change in local places: How scale matters. Clim. Chang. 1999, 43, 601-628.

(C) 2015 by the authors; licensee MDPI, Basel, Switzerland. This article is an open access article distributed under the terms and conditions of the Creative Commons by Attribution (CC-BY) license (http://creativecommons.org/licenses/by/4.0/). 